\title{
Uma análise comparativa do impacto dos fatores individuais e de vizinhança sobre os riscos de vitimização
}

\author{
Doriam Borges*
}

\begin{abstract}
Resumo
Este estudo introduzo controle social público na investigação do impacto dos fatores da vizinhança e das características de seus residentes sobre o risco de vitimização em quatro localidades: nos Estados do Mato Grosso e Santa Catarina, na Cidade do Rio de Janeiro e no Bairro de Santo Amaro, em Recife. 0 controle social público se refere à habilidade da vizinhança em assegurar recursos externos necessários para a redução do crime e da vitimização. Descobrimos que vizinhanças com altos níveis de controle social público e laços sociais mais fortes tendem a reduzir os riscos individuais de vitimização. Vale ressaltar que os resultados não foram parecidos em todas as localidades estudadas, mas percebemos que o risco de vitimização pode ser explicado tanto por fatores do nível do indivíduo quanto da vizinhança.
\end{abstract}

\section{Palavras-chave}

Vitimização. Violência. Controle social..

\begin{abstract}
This study introduces the public social control in the investigation of the impact of neighborhood factors and the characteristics of its residents about the risk of victimization in four locations: in the states of Mato Grosso and Santa Catarina, in the Rio de Janeiro City and District of St Amaro, Recife. The public social control refers to the ability of the neighborhood to ensure external resources required for the reduction of crime and victimization. We found that neighborhoods with high levels of public social control and stronger ties members tend to reduce individual risk of victimization. Note that the results were not similar in all the studied localities, but realized that the risk of victimization can be explained both by the level of the individual factors as the neighborhood.
\end{abstract}

\section{Keywords}

Victimization. Violence. Social control.

\footnotetext{
* Professor adjunto do Instituto de Ciências Sociais (ICS) da Universidade do Estado do Rio de Janeiro (UERJ); doutor em Sociologia pelo Instituto Universitário de Pesquisas do Rio de Janeiro (IUPERJ); mestre em Estudos Populacionais e Pesquisas Sociais pela Escola Nacional de Ciências Estatísticas (ENCE) do Instituto Brasileiro de Geografia e Estatística (IBGE); e pesquisador do Laboratório de Análise da Violência (LAV) da Universidade do Estado do Rio de Janeiro (UERJ).
} 


\section{Introdução}

Nos últimos anos, o aumento da criminalidade, o surgimento de novas formas de crime, algumas vezes mais violentas, a insegurança nas ruas, a impunidade e o despreparo das forças policiais aumentaram a insatisfação da sociedade brasileira a tal ponto que tornaram a questão da violência um dos principais temas do debate público e social. As questões da violência e da criminalidade, além de terem se tornado temas importantes da agenda publica dos últimos anos, também passaram a ser estudadas em diferentes disciplinas de investigação social.

A insatisfação dos cidadãos está presente nas opiniões apresentadas por parte dos meios de comunicação, em manifestações públicas e, especialmente, pelas mudanças no uso dos espaços públicos, pelo aumento do uso de recursos de segurança privada, pela desconfiança revelada na ausência do envolvimento social na reformulação de casas e construção de condomínios para se tornar enclaves fortificados (CALDEIRA, 2000). A insegurança das pessoas é um dos grandes problemas sociais que enfrentamos no Brasil. Notamos que tanto a opinião pública quanto a dos pesquisadores de diferentes disciplinas das ciências sociais têm sido fundamentais para aquecer o debate sobre a violência e a criminalidade ao longo das últimas décadas.

Nesse sentido, a partir de pesquisas de opinião pública com blocos voltados para a obtenção de informações sobre os aspectos ligados à vitimização, tornase possível desenvolver estudos empíricos associados a construções teóricas relevantes dentro da perspectiva da compreensão do fenômeno da violência e da criminalidade.

Neste estudo, vamos apresentar o controle social público e estudar o risco de vitimização criminal através de surveys realizados em quatro diferentes localidades. Não obstante, vamos desenvolver modelos para examinar simultaneamente o impacto de fatores nos níveis contextuais e individuais sobre o risco de vitimização (ROUNTREE et al., 1994; SAMPSON; WOOLDREDGE, 1987). Ao incorporar o controle social público na análise da vitimização, estaremos contribuindo com a discussão do tema da criminalidade, tendo em vista que a maioria dos estudos, ao conceituar fatores contextuais, o faz em termos de condições econômicas, demográficas e familiares. Ao avaliar o impacto do controle social público, este estudo é consistente com os esforços teóricos que enfatizam como as decisões políticas desenvolvidas pelas elites têm influenciado a dinâmica da vizinhança, o posicionamento sobre a habitação pública (BURSIK, 1989), 
a desordem social e física (SKOGAN, 1990), e a segregação residencial (MASSEY; DENTON, 1993). Ao avaliar o papel do controle social público, devemos verificar se os benefícios na redução do risco de vitimização são maiores nas vizinhanças desfavorecidas do que em relação às mais abastadas. Pode-se prever tal resultado dadas as diferenças nos níveis de controle social público encontrado em vizinhanças desfavorecidas, quando comparadas com as mais ricas. Vizinhanças desfavorecidas normalmente têm níveis relativamente baixos de controle social público (SKOGAN; HARTNETT, 1997). Tendo em vista esses níveis de controle, qualquer aumento dos laços na vizinhança com agentes públicos somados a recursos externos poderia representar um enriquecimento social significativo que, por sua vez, poderá se traduzir em uma redução significativa do risco de vitimização. Vizinhanças ricas, ao contrário, já desfrutam de níveis altos de controle social público. Ademais, melhorias no controle social público não apresentam resultados significativos em localidades onde os riscos de vitimização já são baixos. Se o controle social público, de fato, oferece uma solução positiva para a vitimização criminal nas vizinhanças desfavorecidas, isso sugere que há uma solução politicamente viável, dado o papel fundamental que os moradores desempenham na garantia do controle social público ou facilitação das estratégias de policiamento comunitário (PIQUERO et al., 1998).

\section{Nivel Individual}

Nosso foco nesta seção é apresentar os fatores relacionados ao risco de vitimização violenta entre os indivíduos. Aqui, vamos abordar as seguintes questões: qual a distribuição entre as características individuais, tais como idade, sexo, raça, estado civil e nível socioeconômico entre os vitimizados? Essas diferenças são estáveis em diferentes lugares? Como as diferenças no risco de vitimização relativas aos indivíduos são explicadas pelas teorias de vitimização? Vamos começar com uma breve visão genérica dos aspectos gerais da vitimização violenta concernentes ao indivíduo.

As pesquisas de vitimização nos últimos anos têm produzido vários resultados consistentes em todo o mundo. Um dos principais resultados desse tipo de pesquisa mostra o risco de uma pessoa se tornar vítima de um crime. Por exemplo, o risco de uma pessoa sofrer um assalto em 2008 no Município do Rio de Janeiro foi estimado em cerca 11\%. O risco de sofrer uma vitimização por roubo no Mato Grosso foi consideravelmente maior do 
que no Rio de Janeiro (17,6\%). Embora esse risco possa parecer baixo em uma base anual, o risco de violência por qualquer crime em particular é muito alto. Por exemplo, em 2011, a taxa de homicídio no Brasil foi de 28,2 por 100 mil habitantes, mas o risco de vida de ser assassinado é diferente, segundo os grupos. Para as mulheres brancas, a taxa foi de 5,5 por $100 \mathrm{mil}$ habitantes; para os homens brancos, a taxa foi de 31 por 100 mil habitantes; para as mulheres negras, a taxa foi de 6,2 por 100 mil habitantes, e para os homens negros, a taxa foi de 64,3 por 100 mil habitantes (Sistema de Informações sobre Mortalidade - SIM / Ministério da Saúde).

Como sugerido pelas diferenças nos riscos de homicídios ao longo da vida, a segunda maior descoberta em análises concernentes aos indivíduos é que a distribuição de vitimização violenta não é aleatória. Pelo contrário, o risco de sofrer violência pessoal varia consideravelmente entre os grupos demográficos e sociais (BORGES, 2008; BEATO et al, 2004; HINDELANG, 1976; HINDELANG et al., 1978; COHEN et al., 1981; GOTTFREDSON; HINDELANG, 1981; SKOGAN, 1981; GOTTFREDSON, 1986; MIETHE $e t$ al. 1987). O padrão de diferenças sistemáticas encontradas entre os diversos subgrupos demográficos e socioeconômicos tem sido bastante consistente em análises que utilizam os dados de diferentes pesquisas de vitimização no Brasil (PIQUET; FAJNZYLBER, 2001). Padrões de associação semelhantes aos encontrados no Brasil também foram encontrados nas análises utilizando dados de outros países, como nos Estados Unidos (COHEN et al., 1981; GOTTFREDSON; HINDELANG, 1981; SKOGAN, 1981; GOTTFREDSON, 1986); na Inglaterra (HOUGH; MAYHEW, 1983) e na Holanda (van DIJK; STEINMETZ, 1983).

Essas associações relativas aos indivíduos formaram a base das teorias do estilo de vida (HINDELANG, 1976; HINDELANG et al., 1978; GAROFALO, 1987) e das atividades rotineiras (COHEN; FELSON, 1979; COHEN et al., 1981) utilizadas para explicar o risco de vitimização. A proposta essencial dessas teorias é que a convergência no tempo e no espaço de alvos atrativos e a ausência de guardiões pode levar ao aumento da criminalidade, independentemente das condições estruturais e culturais que podem motivar as pessoas a se envolverem em atividades criminosas (por exemplo, desemprego, valores subculturais, impunidade etc.). Derivado dessa proposição geral, o princípio da teoria do estilo de vida indica que as pessoas são mais propensas a serem vitimizadas quando são desproporcionalmente associadas ou entram em contato com os membros de grupos demográficos que apresentam características consideradas significativas de delinquência 
(HINDELANG et al., 1978). Homens, jovens e solteiros, por exemplo, são mais propensos a desenvolver atividades sociais fora de casa do que os casados ou pessoas idosas do sexo feminino, e, portanto, são mais propensos a colocar-se em situações em que a exposição à vitimização é maior. Além disso, pessoas mais jovens podem sofrer um risco maior de vitimização violenta do que as pessoas mais velhas, porque os primeiros são mais predispostos a se associar com outros jovens que estão, desproporcionalmente, se envolvendo com a violência (HINDELANG et al., 1978). O modelo teórico das atividades rotineiras foi proposto por Cohen e Felson (1979). Nele, uma ocorrência criminal necessita da composição formada por um indivíduo motivado a cometer o crime, uma vítima para esse crime é a falta de guardiões capazes de deter a vitimização. Posteriormente, o modelo teórico das atividades rotineiras foi ampliado por Cohen et al. (1981), que introduziu mais duas dimensões para explicar os riscos de vitimização: exposição e atratividade do alvo potencial.

As limitações das teorias das atividades rotineiras e do estilo de vida já foram discutidas longamente pela literatura (GOTTFREDSON, 1986; MAXFIELD, 1987; GAROFALO, 1987; MIETHE et al., 1987). A crítica mais comum entre as pesquisas empíricas tem sido a medição inadequada de variáveis explicativas; as características demográficas e sociais dos indivíduos têm sido usadas principalmente como proxies ou indicadores indiretos para as atividades relacionadas ao estilo de vida das pessoas. As características sociais e demográficas são entendidas e utilizadas para explicar os efeitos sobre o risco de vitimização, pois determinam, em grande medida, as diferenças sistemáticas no papel estruturado do comportamento, através das diferenças de expectativas, de restrições, de oportunidades e de preferências (COHEN et al., 1981). A principal crítica de grande parte da literatura é, portanto, que as medidas diretas das atividades de estilo de vida não são incluídas nos modelos, sendo comtempladas apenas as características sociais e demográficas (HINDELANG et al., 1978; COHEN et al., 1981; GOTTFREDSON, 1986; MIETHE et al., 1987; GAROFALO, 1987). Os tipos exatos de comportamentos que colocam os indivíduos em maior risco de violência ainda não receberam a devida atenção por parte das pesquisas.

Em função da falta de indicadores diretos sobre o estilo de vida, alguns estudos incluem medidas de atividades, tais como a situação de emprego, que verifica, especificamente, o que as pessoas fazem durante um período relativamente grande do seu dia. É relevante ressaltar que as atividades noturnas longe de casa são consideradas pelos autores como aquelas 
mais propensas a envolver a ausência de guardiões ou o maior contato com infratores (HINDELANG et al., 1978; COHEN et al., 1981), o que aumenta as chances de vitimização. Esses fatores de atividades noturnas e diurnas longe de casa foram consideradas por Miethe et al. (1987) em sua análise da vitimização violenta. Eles descobriram que, embora o grau de atividade noturna tenha influenciado significativa e positivamente o risco de vitimização violenta, o efeito foi menor em magnitude do que a maioria das outras variáveis demográficas consideradas. Além disso, a inclusão dessas medidas de atividade não diminuiu significativamente a magnitude dos efeitos de sexo, renda, estado civil e idade. Por outro lado, a maior atividade diurna foi medida e mostrou não afetar o risco de vitimização violenta. À luz desses resultados, Miethe et al. (1987) concluíram que há pouco apoio para a função de mediação das variáveis de atividades rotineiras e de estilo de vida sobre as variáveis demográficas para explicar a vitimização violenta. Por outro lado, houve efeitos muito maiores do estilo de vida sobre a vitimização de roubo.

Esses resultados são intrigantes, mas não definitivos. Primeiro, a atividade noturna foi medida de forma dicotômica e, consequentemente, pode subestimar o risco de vitimização por pessoas que se envolvem em atividades à noite com mais frequência. Em segundo lugar, enquanto medida, essa variável não foi capaz de captar as atividades "longe de casa", nem se o indivíduo estava sozinho, com estranhos, com amigos ou com familiares. Em terceiro lugar, a mensuração da variável da atividade diurna foi construída com base na previsibilidade dos comportamentos. Em outras palavras, as pessoas que vão para a escola foram incluídas na mesma categoria que aquelas que vão para o trabalho, pois sair e voltar para suas casas podem ser atividades previsíveis ao longo do dia - um elemento das atividades rotineiras assumido como sendo de interesse para os infratores motivados. No entanto, o grupo de comparação para a principal atividade abrangia donas de casa, aposentados, pessoas incapazes de trabalhar e desempregados (SAMPSON; LAURITSEN, 1994). Assim, foram incluídos na mesma categoria os grupos com alto risco (desempregados) e os com baixo risco (donas de casa e aposentados) de vitimização. Problemas de medição podem ter sido responsáveis pela falta de efeito da atividade diurna sobre o risco de vitimização violenta (SAMPSON; LAURITSEN, 1994).

Testes mais diretos sobre a hipótese das atividades rotineiras e do estilo de vida foram realizados com dados de diferentes países (van DIJK; STEINMETZ, 1983; GOTTFREDSON, 1986). Análises como essas não foram realizadas 
no Brasil, principalmente porque a principal fonte de dados - as pesquisas de vitimização - não inclui medidas de atividades rotineiras detalhadas o suficiente para uma avaliação adequada dessas hipóteses. Com efeito, a falta de medidas diretas fez com que as hipóteses das atividades rotineiras e do estilo de vida fossem extremamente difíceis de testar no Brasil. Em geral, a literatura nacional tem lançado mão de medidas indiretas para estudar essas teorias de vitimização criminal (BORGES, 2008; BEATO et al., 2004).

Por outro lado, medidas diretas de atividades rotineiras derivadas de pesquisas internacionais, especialmente o número de noites nas quais o indivíduo se expõe por semana sozinho, atividades realizadas tipicamente à noite, o tipo de transporte utilizado, o uso de bebida alcoólica, e comportamento ofensivo autodeclarado - foram significativamente associados ao risco de vitimização pessoal (SAMPSON; LAURITSEN, 1994). Corrado et al. (1980), por exemplo, encontraram um padrão semelhante nos dados demográficos canadenses em comparação com os dados do Brasil. No entanto, a inclusão de uma medida bruta de atividades fora de casa (dividido pela mediana) teve um efeito significativo sobre o risco de vitimização violenta (roubo e agressão sexual): pessoas que passam mais tempo longe de casa têm aproximadamente três vezes mais chances de serem vitimizadas do que aquelas que passam mais tempo em casa. A inclusão dessa variável não diminuiu os efeitos do sexo e da idade, mas reduziu a magnitude do efeito do estado conjugal. Smith (1982) também afirma que essas atividades fora de casa que aumentam o contato com estranhos são mais vitimogênicas. Da mesma forma, Hough e Mayhew (1983), van Dijk e Steinmetz (1983) e Gottfredson (1986) descobriram que a frequência e o tipo de atividades noturnas relacionados ao uso de transporte público e a ações como beber ou sair para bares aumentam a vitimização pessoal na Grã-Bretanha, enquanto as atividades como ir à igreja estão associadas com o menor risco. Além disso, usando os dados da Grã-Bretanha, Hough e Mayhew (1983) descobriram que a frequência de atividades noturnas combinada com a quantidade de bebida alcoólica consumida era importante para determinar o risco de vitimização entre as pessoas com menos de 30 anos de idade. Finalmente, Kennedy e Forde (1990), utilizando dados do Canadá, analisaram os efeitos relativos a uma variedade de atividades rotineiras sobre vitimização por agressão e roubo. Os autores relatam que certos tipos de atividades - especialmente o número de vezes que se vai a bares ou que se faz caminhadas à noite - estão diretamente relacionados com os riscos de vitimização violenta. Além disso, esses efeitos persistiram, apesar dos controles estatísticos a partir de fatores 
demográficos tradicionais (idade, sexo, renda familiar) e de características do bairro (por exemplo, a porcentagem de famílias com baixa renda).

Em suma, diferentes autores indicam que detalhes sobre o tipo das atividades diurnas e noturnas são necessárias para avaliar adequadamente o estilo de vida e as atividades rotineiras nos modelos de vitimização violenta. Análises anteriores utilizando os dados de pesquisas de vitimização no Brasil foram limitadas devido à indisponibilidade de medidas, tais como o tipo de atividades noturnas envolvido. Assim, é possível que os padrões sobre os efeitos diretos do estilo de vida sejam exclusivos para países como a GrãBretanha, onde as condições culturais e estruturais (por exemplo, composição racial) são bastante diferentes em relação ao Brasil. Consequentemente, só podemos falar sobre os fatores de estilo de vida no nível individual associados com o risco de vitimização violenta para a população brasileira, através dos tradicionais fatores sociais e demográficos (idade, sexo, cor e renda familiar), que estão relacionados a diferenças no risco de vitimização violenta. Claramente, futuras investigações sobre vitimização precisam se concentrar mais especificamente no desenvolvimento do nível individual e das medidas necessárias para testar as hipóteses das teorias do estilo de vida e das atividades rotineiras no Brasil.

\section{0 papel do controle social da comunidade no processo de vitimização}

O controle social da comunidade se refere à capacidade de uma comunidade se autorregular através do controle do comportamento dos residentes e seus visitantes (BURSIK; GRASMICK, 1993). A teoria da desorganização social propõe que a mediação do controle social da comunidade tem efeito sobre a redução da criminalidade na vizinhança (BURSIK, 1989; SHAW; MCKAY, 1942). Empiricamente, isso significa que o efeito das condições da vizinhança, como a pobreza, a criminalidade e a vitimização devem desaparecer ou reduzir substancialmente, quando o controle social da comunidade for levado em conta (SAMPSON; GROVES, 1989; SAMPSON et al., 1997; WARNER; ROUNTREE, 1997).

Ao examinar essa hipótese, os pesquisadores se concentraram principalmente nos laços sociais locais - as relações entre os moradores - como fontes importantes do controle social da comunidade. Estudos têm enfatizado o impacto da vizinhança e do controle social informal sobre a criminalidade 
(BURSIK; GRASMICK, 1993). A vizinhança, além da extensão territorial, se refere à capacidade de interação social entre os vizinhos, através das conversas, das trocas ou do tempo em que ficam juntos. Pesquisas demonstram que vizinhanças que possuem níveis mais elevados de moradores que usufruem de trocas sociais são associadas a taxas de criminalidade mais baixas (SAMPSON; GROVES, 1989; WARNER; ROUNTREE, 1997). Já o controle social informal se refere à capacidade da vizinhança de supervisionar o comportamento dos residentes (BURSIK; GRASMICK, 1993; HUNTER, 1985). O controle social informal pode assumir uma variedade de formas, incluindo vizinhos que cuidam uns dos outros e chamam a polícia ao primeiro sinal de problemas (BURSIK; GRASMICK, 1993; SAMPSON; GROVES, 1989; SAMPSON et al., 1997). Sampson et al. (1997), por exemplo, descobriram que a coesão social acompanhada pela vontade de intervir em nome do interesse da vizinhança levaram a importantes reduções na criminalidade e na vitimização em bairros de Chicago.

Partindo das proposições da teoria do capital social e dos resultados de que as redes sociais de apoio podem melhorar o bem-estar geral, a hipótese é de que altos níveis de redes de apoio social podem levar a altos níveis de satisfação no bairro e a alta eficácia coletiva. Altos níveis de apoio social também são entendidos como um impacto positivo na adoção de medidas de prevenção e proteção, com base na especulação de que os indivíduos inseridos em redes de apoio serão mais propensos a empreender mecanismos de segurança para proteger a si mesmos e às pessoas próximas a eles do crime. Apesar da aparente ambiguidade em relação aos efeitos das redes sociais sobre o medo do crime, a hipótese de que altos níveis de apoio social podem influenciar negativamente o medo do crime tem tido um papel importante dentro da literatura internacional.

A noção de eficácia coletiva refere-se às expectativas compartilhadas e engajamento cívico mútuo pelos membros da comunidade no controle social local, com ênfase na capacidade conjunta dos moradores para agir em conjunto para gerar soluções para os problemas locais (SAMPSON, 2004). Exemplos de iniciativas de segurança da comunidade fundamentadas em princípios de eficácia coletiva incluem Neighborhood Watch e fóruns públicos, em que os problemas da comunidade são discutidos e localmente conduzidos e soluções são geradas. Considerando a variedade de mecanismos de segurança pessoal e coletiva, a eficácia coletiva pode gerar um efeito preventivo para o crime.

Apesar de existirem muitos trabalhos que abordem os laços estabelecidos 
entre os moradores da vizinhança, poucos estudos da desorganização social têm investigado como os laços com agentes públicos e com a polícia - uma outra dimensão do controle social da comunidade - influenciam a criminalidade e a vitimização (BURSIK; GRASMICK, 1993), sobretudo no Brasil. Dentre os poucos trabalhos com essa abordagem, destacamos o de Bursik (1989), que examinou se o desenvolvimento de novos projetos habitacionais, um reflexo da tomada de decisões no nível da cidade, estava relacionado com a criminalidade nas vizinhanças de Chicago. Bursik (1989) constatou que os funcionários municipais inseridos nos novos projetos habitacionais em vizinhanças residencialmente instáveis, e que não haviam desenvolvido uma articulação prévia, não conseguiram organizar e negociar uma defesa eficaz para a sua construção. Por sua vez, a colocação de projetos habitacionais nas vizinhanças residencialmente instáveis levou a aumentos substanciais nas taxas de delinquência através do aumento na instabilidade social. As descobertas de Bursik sugerem que a tomada de decisão política é uma consequência no nível da vizinhança do crime e da vitimização. Uma implicação importante de seu estudo é que os residentes devem estabelecer vínculos com as elites da cidade, a fim de influenciar as decisões políticas que afetam suas comunidades, incluindo os seus níveis de criminalidade.

A literatura internacional tem ressaltado a importância do controle social público por diferentes motivos. Em primeiro lugar, o levantamento em trabalhos sobre policiamento comunitário permitiu verificar que, nesses programas, a polícia cultiva relacionamentos com moradores de bairros urbanos, em sua maioria, pobres (KELLING, COLES, 1996; PIQUERO et $a l .$, 1998; SKOGAN, 1990). O sucesso dos esforços da polícia na redução da criminalidade, no entanto, muitas vezes, depende do envolvimento da comunidade no programa comunitário. Kelling e Coles (1996), por exemplo, documentaram como o Prefeito e o Chefe de Polícia de Baltimore criaram uma força-tarefa de órgãos municipais e associações comunitárias que se reuniam regularmente com moradores da comunidade de um bairro desfavorecido. Com o apoio do município, os moradores, por sua vez, foram capazes de melhorar os prédios abandonados, remover o lixo da vizinhança e bloquear os caminhos para impedir os esforços do tráfico de drogas. Essas ações ajudaram a reduzir a criminalidade violenta em $56 \%$ em três anos (KELLING; COLES, 1996). O desenvolvimento de relações com a polícia oferece aos moradores mais do que apenas a redução do crime. Skogan (1990), por exemplo, descobriu que os esforços de policiamento comunitário em Newark levaram para os moradores maior satisfação com sua vizinhança 
e com a polícia, bem como uma diminuição do medo do crime entre os moradores.

Em segundo lugar, a pesquisa sobre a mobilização da vizinhança analisou as possíveis estratégias que os moradores podem depreender para estabelecer laços com as autoridades da cidade e, assim, formar as decisões políticas essenciais para o aprimoramento do bairro (ROONEY, 1995). Partindo do pressuposto de que os moradores de bairros desfavorecidos não costumam usufruir de fortes laços com os governos municipais e com a polícia (HENNING, 1982), esses estudos mostraram que os residentes deveriam primeiro se mobilizar para ganhar a atenção das autoridades municipais. A importância de as comunidades serem bem organizadas sugere que os laços sociais locais (relações entre os vizinhos) desempenham um papel importante na formação do controle social público.

\section{Dados e Métodos}

Neste trabalho utilizamos os dados de quatro pesquisas de vitimização realizadas pelo DataUFF: Pesquisa sobre Condições de Vida e Vitimização na Região Metropolitana do Rio de Janeiro, realizada em 2008; Pesquisa de Vitimização no Estado do Mato Grosso, realizada em 2010; Pesquisa de Imagem da Segurança Pública no Estado de Santa Catarina, realizada em 2012; e Pesquisa de Imagem da Segurança no Bairro de Santo Amaro - Recife, realizada em 2013 .

Essas pesquisas de vitimização possuem unidades espaciais distintas, ou seja, podemos classificar as observações dos dados em três escalas: Estado (Mato Grosso e Santa Catarina), Região Metropolitana (Rio de Janeiro) e Bairro (Santo Amaro). Com relação aos dados representados em áreas, destacamos o fato de que as estimativas obtidas na análise dependem das diversas formas em que essas áreas são agrupadas, podendo-se obter resultados diferentes simplesmente pela alteração das suas fronteiras. Esse problema é conhecido como problema da unidade de análise modificável. Assim, para minimizar seu impacto com relação a esses estudos, devemos procurar utilizar a melhor escala de levantamento de dados disponível, sempre buscando critérios de agregação dos dados que sejam consistentes com os objetivos do estudo. O ideal seria que a unidade espacial nas quatro pesquisas fosse a mesma. Como não há possibilidade de unificar a unidade nas pesquisas, podemos, ao menos, em uma delas, modificar a sua escala espacial e torná-la analiticamente mais interessante. Foi o que fizemos com 
o Rio de Janeiro. Ao invés de trabalharmos com a Região Metropolitana, trabalhamos com a cidade do Rio de Janeiro. Com isso, temos três novas unidades espaciais: Estado, Cidade e Bairro. A despeito das dificuldades na comparação devido às questões já descritas, a análise dos resultados relativos nessas três unidades pode gerar discussões interessantes, considerando a perspectiva teórica utilizada neste estudo.

\section{Uma análise descritiva das taxas de vitimização}

As pesquisas de vitimização vêm ganhando terreno nas últimas décadas, tanto em nível nacional como internacional. Essas pesquisas abordam questões como as teorias explicativas da vitimização, a relação entre a vítima e o agressor, as interações entre as vítimas e o sistema de justiça criminal, bem como a conexão das vítimas com outros grupos sociais e com as instituições policiais. Segundo Lahosa (2002), existem referências a um primeiro levantamento das vítimas de crime realizado na cidade dinamarquesa de Aarhus, em 1730. Assim como a investigação sobre o suicídio e o crime pelos departamentos franceses, realizada durante a primeira metade do século XIX, pelo diretor Jean Baptiste Joseph Fourier (HACKING, 1990).

Um grande esforço foi desenvolvido pelas Nações Unidas, que coordenou um survey em mais de 70 países. O International Crime Victim Survey (ICVS) é um programa de padronização de metodologia de pesquisa de vitimização, realizado em diversos países, com o objetivo de compará-los. Esse programa de padronização foi desenvolvido pelo United Nations Interregional Crime and Justice Research Institute (UNICRI) e procurou ampliar a área geográfica de abrangência do projeto, incluindo países de diferentes continentes.

Em 1989, foi realizada a primeira aplicação de surveys internacionais em 14 países. Isso permitiu obter um panorama da criminalidade em 1988 daqueles países envolvidos, através de uma cooperação firmada entre Holanda, Reino Unido e Suíça. As entrevistas foram realizadas por telefone, com uso da tecnologia CATI (Computer Assisted Telephone Interviewing).

Em 1992 ocorreu a segunda aplicação de surveys, envolvendo 33 países, dos quais 20 utilizaram a técnica de entrevistas pessoais (face-to-face). Em 1996 foi realizada a terceira aplicação, contemplando 48 países, dos quais 36 utilizaram a técnica face-to-face. A quarta rodada foi em 2000, em 48 países. A mais recente rodada da pesquisa do ICVS aconteceu em 2004-2005, em 15 Estados mais antigos da União Europeia. Ela foi realizada em parceria com o Instituto Gallup/Europe, e com o European Crime Survey com supervisão 


\section{do UNICRI.}

O objetivo final da medição da vitimização pode definir a direcionalidade das políticas públicas de segurança, de forma eficaz e respeitosa aos direitos de todos os cidadãos.

Desse modo, podemos dizer que a pesquisa de vitimização é um instrumento valioso tanto para medir o crime como para estimar com maior precisão o perfil das vítimas, bem como avaliar o impacto do fato delituoso na vida dos indivíduos, o que de outra forma, através dos registros de ocorrência, seria improvável.

Nesta seção, serão apresentados alguns dados sobre vitimização, além de um perfil simples da vítima. No Gráfico 1 podemos verificar que a estimativa da taxa de vitimização por roubo e furto nos últimos 12 meses varia segundo o local da pesquisa.

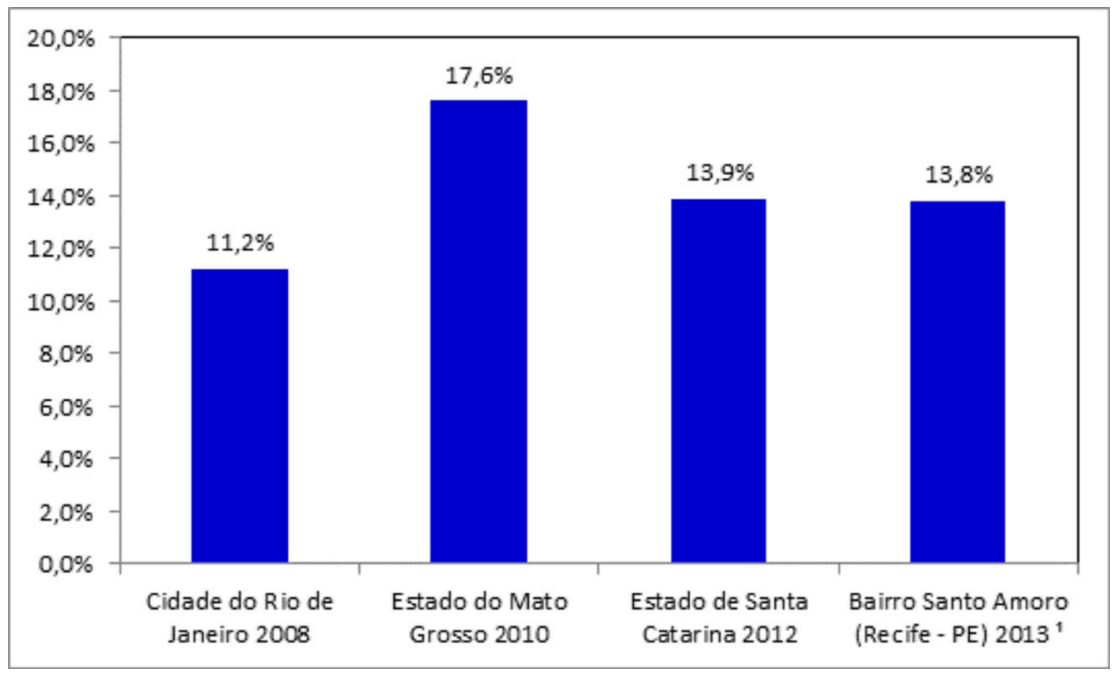

Gráfico 1: Taxa de vitimização nos últimos 12 meses

Fonte: DataUFF - Pesquisa de Condições de Vida e Vitimização no Rio de Janeiro - 2008; Pesquisa de Vitimização no Estado do Mato Grosso - 2010; Pesquisa de Imagem da Segurança Pública no Estado de Santa Catarina - 2012; Pesquisa de Imagem da Segurança Pública no Bairro de Santo Amaro, Recife - PE - 2013.

${ }^{1}$ No questionário da pesquisa realizada no Bairro Santo Amaro, o período de referência da pergunta sobre a experiência de vitimização foi de 5 anos. 
Algumas pesquisas analisam os efeitos de características demográficas e sociais sobre a vitimização, demonstrando que indivíduos que são, por exemplo, homens, jovens, solteiros ou moradores de zonas urbanas sofrem um risco maior de vitimização do que aqueles que pertencem a outros grupos (BEATO; PEIXOTO; ANDRADE, 2004).

O sexo da vítima, por exemplo, pode ser um fator importante na explicação das variações nas taxas de vitimização em função das diferenças de estilo de vida e comportamento entre os homens e as mulheres. A partir dessa abordagem, os homens tendem a apresentar maiores chances de serem vitimizados do que as mulheres, devido a sua maior exposição, tendo como referência a teoria das atividades rotineiras (FELSON; COHEN, 1980; COHEN et al., 1981). Analisando as taxas de vitimização por sexo apresentadas na Tabela 1, verificamos que a diferença entre a vitimização e o sexo do entrevistado foi significativa apenas na Cidade do Rio de Janeiro e no Bairro de Santo Amaro. Esse resultado é interessante, pois mostra as diferenças culturais, sociais e econômicas de cada lugar. Ademais, há uma questão que talvez seja relevante e que devemos ter cuidado nesta análise e nas demais, que é o fato de estarmos comparando lugares cuja unidade espacial é diferente, ou seja, estamos confrontando os resultados de pesquisas realizadas nos níveis do estado, cidade e bairro.

Outro fator importante nos estudos sobre os riscos de vitimização é o momento do ciclo de vida do indivíduo. Segundo alguns autores, os indivíduos nas etapas iniciais do ciclo de vida (infância) bem como os mais idosos tendem a apresentar menor exposição, uma vez que tendem a frequentar menos os lugares públicos - a proporção de tempo em que essas pessoas passam em família é maior e, consequentemente, suas interações sociais são limitadas. 
Tabela 1: Taxa de vitimização nos últimos 12 meses, segundo perfil

\begin{tabular}{|c|c|c|c|c|c|c|c|c|}
\hline & \multicolumn{2}{|c|}{$\begin{array}{c}\text { Cidade do Rio de } \\
\text { Janeiro } 2008\end{array}$} & \multicolumn{2}{|c|}{$\begin{array}{c}\text { Estado do Mato } \\
\text { Grosso } 2010\end{array}$} & \multicolumn{2}{|c|}{$\begin{array}{c}\text { Estado de Santa } \\
\text { Catarina } 2012\end{array}$} & \multicolumn{2}{|c|}{$\begin{array}{c}\text { Bairro de Santo } \\
\text { Amaro (Recife - PE) } \\
2013^{1}\end{array}$} \\
\hline & $\begin{array}{c}\text { Taxa de } \\
\text { Vitimização }\end{array}$ & Sig. & $\begin{array}{c}\text { Taxa de } \\
\text { Vitimização }\end{array}$ & Sig. & $\begin{array}{c}\text { Taxa de } \\
\text { Vitimização }\end{array}$ & Sig. & $\begin{array}{c}\text { Taxa de } \\
\text { Vitimização }\end{array}$ & Sig. \\
\hline \multicolumn{9}{|c|}{ Sexo } \\
\hline Masculino & $13,1 \%$ & $*$ & $17,4 \%$ & & $14,6 \%$ & & $17,2 \%$ & $* *$ \\
\hline Feminino & $9,3 \%$ & & $17,8 \%$ & & $13,1 \%$ & & $11,0 \%$ & \\
\hline \multicolumn{9}{|c|}{ Faixa Etária } \\
\hline 16 a 24 anos & $20,3 \%$ & $*$ & $20,5 \%$ & $* *$ & $12,5 \%$ & & $15,4 \%$ & $* *$ \\
\hline 25 a 34 anos & $15,5 \%$ & & $18,1 \%$ & & $14,0 \%$ & & $20,5 \%$ & \\
\hline 35 a 44 anos & $7,4 \%$ & & $18,2 \%$ & & $13,5 \%$ & & $15,0 \%$ & \\
\hline 45 a 59 anos & $8,3 \%$ & & $17,1 \%$ & & $15,2 \%$ & & $7,6 \%$ & \\
\hline 60 anos ou mais & $5,8 \%$ & & $14,1 \%$ & & $13,9 \%$ & & $10,0 \%$ & \\
\hline \multicolumn{9}{|c|}{ Estado Civil } \\
\hline Solteiro & $14,9 \%$ & $*$ & $19,4 \%$ & $* *$ & $14,9 \%$ & & $14,5 \%$ & \\
\hline Não Solteiro & $9,3 \%$ & & $17,0 \%$ & & $13,3 \%$ & & $13,4 \%$ & \\
\hline \multicolumn{9}{|c|}{ Cor } \\
\hline Branco & $11,6 \%$ & $*$ & $18,1 \%$ & & $14,7 \%$ & $* *$ & $16,4 \%$ & \\
\hline Negro & $10,7 \%$ & & $17,4 \%$ & & $11,0 \%$ & & $13,0 \%$ & \\
\hline \multicolumn{9}{|c|}{ Renda Familiar } \\
\hline Mais de $5 \mathrm{SM}$ & $14,2 \%$ & $*$ & $23,8 \%$ & $*$ & $20,7 \%$ & $*$ & $25,0 \%$ & $* *$ \\
\hline Mais de 3 até 4 SM & $10,9 \%$ & & $23,3 \%$ & & $13,7 \%$ & & $6,5 \%$ & \\
\hline Mais de 2 até 3 SM & $12,0 \%$ & & $17,6 \%$ & & $17,0 \%$ & & $15,7 \%$ & \\
\hline Mais de 1 até 2 SM & $8,0 \%$ & & $16,5 \%$ & & $11,2 \%$ & & $14,7 \%$ & \\
\hline Até $1 \mathrm{SM}$ & $7,0 \%$ & & $13,7 \%$ & & $10,1 \%$ & & $11,0 \%$ & \\
\hline
\end{tabular}

Fonte: DataUFF - Pesquisa de Condições de Vida e Vitimização no Rio de Janeiro - 2008; Pesquisa de Vitimização no Estado do Mato Grosso - 2010; Pesquisa de Imagem da Segurança Pública no Estado de Santa Catarina - 2012; Pesquisa de Imagem da Segurança Pública no Bairro de Santo Amaro, Recife - PE - 2013.

(*) Diferença estatisticamente significante com uma probabilidade de $99 \%$.

(**) Diferença estatisticamente significante com uma probabilidade de $95 \%$.

1 No questionário da pesquisa realizada no Bairro Santo Amaro, o período de referência da pergunta sobre a experiência de vitimização foi de 5 anos.

Na análise comparativa apresentada na Tabela 1, podemos perceber que apenas no Estado de Santa Cataria o fator faixa etária não foi significativo. Analisando os resultados significativos do fator faixa etária, percebemos que os grupos de pessoas com idade entre 16 e 24 anos são os que apresentaram maiores taxas de vitimização na Cidade do Rio de Janeiro e no Estado do Mato Grosso, enquanto que no Bairro de Santo Amaro o grupo etário com maior taxa foi o de 25 a 34 anos. Apesar dessas diferenças, podemos ter uma conclusão geral de que os jovens tendem a apresentar uma taxa mais elevada de vitimização do que os mais velhos. Seguindo essa abordagem, 
podemos atribuir aos fatores "exposição", "menor capacidade de proteção" e "proximidade entre vítima e agressor" a explicação para esses resultados (FELSON; COHEN, 1980; COHEN et al., 1981). Indivíduos mais jovens em sua maioria são solteiros, frequentam mais lugares públicos sem se preocupar muito com sua própria proteção.

A associação esperada entre estado civil e as chances de vitimização está diretamente relacionada com o fator de exposição. De acordo com a literatura, os solteiros apresentam riscos mais altos de vitimização do que os outros grupos (casados, separados/desquitados e viúvos). Os resultados encontrados nas pesquisas realizadas na Cidade do Rio de Janeiro e no Estado de Mato Grosso confirmam esse pressuposto. Os solteiros apresentaram maiores taxas de vitimização do que os não solteiros, pois possuem um estilo de vida que os torna mais expostos a situações de risco.

Outro aspecto analisado nas pesquisas foi a cor dos entrevistados. O Brasil, apesar de ser um país com altos índices de desigualdade racial, apresenta baixos níveis de segregação espacial por cor, o que leva essa variável a não capturar bem o efeito de proximidade e proteção, atribuídas a ela pela literatura (BORGES, 2013). Em sociedades racialmente segregadas, a mobilidade residencial dos indivíduos tende a ser limitada, e indivíduos de grupos minoritários apresentam uma propensão cultural a permanecer em bairros fortemente heterogêneos, o que, por sua vez, pode aumentar as chances de proximidade com os potenciais agressores e a diminuição da capacidade de proteção. Por outro lado, se a população não está segregada racialmente, a cor do indivíduo não terá efeito na determinação das probabilidades de vitimização. Os resultados apresentados na Tabela 1 confirmam essa hipótese para o Estado do Mato Grosso e para o Bairro Santo Amaro, ou seja, não existe diferença estatisticamente significativa entre a cor autodeclarada do indivíduo e a experiência de vitimização.

Diferentes autores utilizam a renda familiar como uma variável para explicar o risco de vitimização de um indivíduo. A renda pode ser um reflexo da posição do indivíduo na estrutura econômica da sociedade, que está relacionada ao fator de atratividade da vítima (FELSON; COHEN, 1980; COHEN et al., 1981), ou seja, as pessoas com renda mais alta são mais atrativas, pois exibem maior retorno econômico esperado pelo crime. Analisando a Tabela 1, podemos perceber que esta foi a única variável significativa nas quatro pesquisas. Os resultados encontrados nas pesquisas confirmam as hipóteses teóricas, ou seja, as pessoas com mais renda tendem a apresentar maiores riscos de vitimização do que aquelas com rendas mais baixas. 


\section{Determinantes da Vitimização}

Nesta seção é apresentada uma definição das variáveis dependente e independentes, com a especificação dos modelos adotados. A seguir, apresentamos os resultados dos determinantes da vitimização criminal na Cidade do Rio de Janeiro, no Estado do Mato Grosso, no Estado de Santa Catarina e no Bairro de Santo Amaro, em Recife - PE.

\section{Variável Dependente}

Vitimização: foi perguntado aos entrevistados se seu carro ou outro bem havia sido roubado ou furtado nos últimos 12 meses $^{1}$. Usando essa informação, criamos variáveis dicotômicas ( 1 o entrevistado foi vitimizado; 0 o entrevistado não foi vitimizado) em cada pesquisa.

\section{Variáveis Independentes}

Controle Social Comunitário: inspirados por Bursik e Grasmik (1993), utilizamos o controle social público, a partir da definição de laços da comunidade com o governo local e com a polícia, duas instituições que controlam recursos e benefícios para a vida da vizinhança. Mensuramos o controle social público como a resposta às cinco perguntas a seguir: 1) Avaliação da oferta de transportes públicos como ônibus na vizinhança;

2) Avaliação do policiamento a pé, em viaturas ou moto na vizinhança; 3) Avaliação da oferta de serviços públicos de saúde na vizinhança; 4) Avaliação da coleta de lixo e entulhos nas ruas da vizinhança; 5) Avaliação da oferta de escolas públicas na vizinhança. Além disso, mensuramos os laços sociais locais a partir de duas perguntas: 1) Poderia contar com os vizinhos para tomar conta da casa enquanto não está?; 2) Poderia contar com os vizinhos para resolver conflitos ou brigas na vizinhança?

Desordem Social e Física: para trabalhar com as condições da vizinhança, utilizamos a abordagem da desordem social e física na vizinhança como variáveis importantes no estudo da vitimização. Para tanto, trabalhamos com as

\footnotetext{
${ }^{1}$ Na pesquisa realizada em Santo Amaro, o período de referência para a pergunta de vitimização foi de 5 anos.
} 
seguintes questões: 1) Existem prédios, casas ou galpões abandonados na vizinhança?; 2) Existem carros abandonados, arrebentados ou desmontados na rua da vizinhança?; 3) Existem terrenos ou lotes vagos cheios de lixo e entulhos ou com mato alto (cercados ou não) na vizinhança; 4) Existem barulhos de tiros na vizinhança.

Teorias das Atividades Rotineiras e Estilo de Vida: Seguindo a perspectiva da teoria das atividades rotineiras, a renda familiar e o sexo são proxies de alvo atrativo. Estado civil e idade, por outro lado, serão utilizados como variáveis representantes da teoria do estilo de vida. Já a cor entrará no estudo como uma variável de controle.

Estudos recentes de vitimização criminal têm enfatizado a inter-relação entre os efeitos individuais e estruturais para explicar os riscos de vitimização. No entanto, esses trabalhos ainda precisam incorporar os modelos de efeito misto - fatores do indivíduo e da vizinhança - com comparações entre diferentes regiões, estados etc. com economias, histórias ou culturas diferentes. O presente estudo aborda a generalização potencial das relações empíricas de nível individual e de vizinhança analisando o risco de vitimização de roubo ou furto em quatro localidades (cidade do Rio de Janeiro, Estados do Mato Grosso e Santa Catarina e o Bairro de Santo Amaro em Recife-PE), comparando os efeitos de variáveis sociodemográficas, de atividade rotineira e estilo de vida como fatores individuais, e de variáveis de desordem, laço e controle social como fatores de vizinhança e usando os dados de quatro pesquisas aplicadas pelo DataUFF.

Recorrendo à análise de Regressão Logística² para estudar o risco de vitimização, pretendemos avaliar a influência das variáveis explicativas relacionadas às abordagens teóricas das atividades rotineiras, estilo de vida, controle social público, laços sociais e desordem social e física. Na Tabela 2, verificamos os resultados dos quatro modelos. De forma geral, os resultados dos modelos confirmam a hipótese principal do estudo de que o risco

\footnotetext{
${ }^{2} \mathrm{O}$ uso dessa técnica para ajustar modelos estatísticos permite identificar quais fatores explicativos possibilitam interpretar adequadamente o perfil do grupo com maior risco/probabilidade de ser vitimizado, utilizando outras variáveis escolhidas a partir de testes de qualidade do ajuste. Tal procedimento permite obter uma medida de como essas variáveis influenciam a probabilidade de uma pessoa ser vitimizada.
} 
de vitimização pode ser explicado por fatores no nível do indivíduo e da vizinhança. Além disso, também podemos perceber ainda que os fatores ligados ao controle social público também influem na probabilidade de vitimização, sobretudo na cidade do Rio de Janeiro.

No primeiro modelo, para a cidade do Rio de Janeiro, todas as variáveis explicativas foram estatisticamente significativas. Entretanto, ao invés de realizarmos a análise por modelo, faremos o estudo por grupo de variáveis, considerando a perspectiva teórica a qual este está representando. Nesse sentido, iniciando pelas atividades rotineiras (FELSON; COHEN, 1980; COHEN et al., 1981), utilizamos duas variáveis para representar essa teoria: sexo e renda familiar. O sexo do entrevistado, quando controlado pelas outras variáveis, deixou de ser significativo no Bairro Santo Amaro. Na Cidade do Rio de Janeiro, essa variável foi significativa, e as estimativas mostram que os homens possuem 1,4 vez mais chances de serem vitimizados do que as mulheres. Esse resultado corrobora com a hipótese de maior exposição ao perigo. A renda familiar, por sua vez, pode servir para mensurar o conceito de oportunidade de um alvo atrativo, na medida em que os indivíduos fornecem pistas na renda sobre o valor da casa em que vivem, o carro que dirigem, ou das roupas e joias que usam. A variável renda familiar é reconhecidamente uma proxy imperfeita para o fator atratividade, uma vez que os indivíduos menos abastados também podem possuir bens que sejam atrativos para potenciais criminosos (FELSON; COHEN, 1980; COHEN et al., 1981). Apesar das limitações com o uso da renda familiar como uma proxy para a atratividade, medidas mais específicas não estavam disponíveis nas pesquisas. De qualquer forma, essa variável foi significativa nos quatro modelos, de forma que aqueles que disseram ter uma renda familiar mais alta possuem mais chances de serem vitimizados quando comparados com os que possuem rendas mais baixas.

Em se tratando da teoria do estilo de vida, a variável faixa etária foi significativa apenas no modelo para a Cidade do Rio de Janeiro. Os resultados dessa variável mostram que, quanto mais jovem, maiores as chances de vitimização, tal como sugere a teoria do estilo de vida (SAMPSON; WOOLDREDGE, 1987; MIETHE; MEIER, 1994), descrita anteriormente. Estado civil também é utilizado para mensurar essa teoria. Como podemos verificar na Tabela 2, somente no Bairro Santo Amaro, em Recife, essa variável não foi significativa. Nos Estados de Mato Grosso e Santa Catarina, os solteiros possuem mais chances de vitimização do que os não solteiros, confirmando a perspectiva teórica do estilo de vida, ou seja, os solteiros 
tendem a se expor mais do que os outros grupos, por isso possuem mais riscos (MIETHE; MEIER, 1994). Por outro lado, curiosamente, na Cidade do Rio de Janeiro, o resultado foi o contrário do esperado.

As variáveis que representam o controle social público foram significativas no modelo para a Cidade do Rio de Janeiro e sinalizam a ideia apresentada pela hipótese de que quanto melhor a avaliação dos serviços públicos (melhores serviços) menores os riscos de vitimização (BURSIK; GRASMICK, 1993). Analisando as Razões de Chances na Tabela 2 para o grupo de variáveis que representam a teoria do controle social público, podemos perceber que as pessoas que avaliaram os serviços públicos como "Ruim" tendem a ter mais chances de vitimização do que aquelas que avaliaram os serviços como "Bom". No modelo de Santa Catarina, a "Avaliação do policiamento a pé, em viaturas ou moto na vizinhança" foi significativa, e na mesma direção que a literatura internacional sugere, isto é, nas vizinhanças que possuem bons recursos de policiamento a pé (ou boa interação com as instituições responsáveis pelos seus serviços), os riscos de vitimização são menores. 


\begin{tabular}{|c|c|c|c|c|c|c|c|c|c|c|c|c|c|c|c|c|c|c|}
\hline 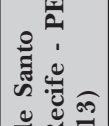 & 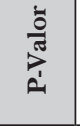 & g. & $\begin{array}{l}\tilde{D} \\
\tilde{N} \\
\tilde{o}\end{array}$ & & $\begin{array}{l}\mathbb{J} \\
\text { : }\end{array}$ & $\left|\begin{array}{c}\tilde{v} \\
\tilde{0} \\
\dot{0}\end{array}\right|$ & 兽 & $\begin{array}{l}m \\
\infty \\
0 \\
0\end{array}$ & & \begin{tabular}{l}
\multirow{D}{0}{} \\
$\infty$ \\
0 \\
0
\end{tabular} & & $\begin{array}{l}\text { Na } \\
\text { in } \\
0 \\
0\end{array}$ & & $\begin{array}{l}1 \\
0 \\
0 \\
0\end{array}$ & $\begin{array}{l}\text { ¿े } \\
\text { on } \\
0\end{array}$ & $\begin{array}{l}\text { No } \\
\text { N } \\
\text { o }\end{array}$ & $\begin{array}{l}8 \\
\mathscr{8} \\
0\end{array}$ & \\
\hline 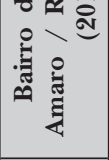 & 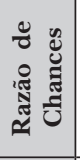 & $\begin{array}{l}8 \\
8 \\
0\end{array}$ & $\begin{array}{l}+ \\
\infty \\
0 \\
- \\
-\end{array}$ & $\underset{8}{8}$ & 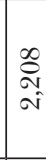 & 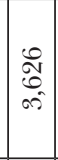 & $\begin{array}{l}\mathcal{q} \\
\text { ầ } \\
\text { ô }\end{array}$ & $\mid \begin{array}{c}\mathfrak{N} \\
\mathbb{N} \\
0 \\
0 \\
0\end{array}$ & $\begin{array}{l}8 \\
8 \\
- \\
-1\end{array}$ & $\begin{array}{l}\overline{\mathscr{\theta}} \\
\tilde{\sigma}\end{array}$ & $\begin{array}{l}8 \\
8 \\
- \\
-1\end{array}$ & $\begin{array}{l}\sqrt{a} \\
\vec{\sim} \\
-\end{array}$ & $\stackrel{8}{8}$ & $\begin{array}{l}1 \\
\infty \\
\infty \\
o v \\
o v\end{array}$ & $\begin{array}{l}\infty \\
\stackrel{1}{+} \\
0 \\
0\end{array}$ & $\stackrel{+1}{\Rightarrow}$ & 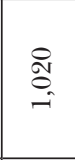 & $\stackrel{8}{8}$ \\
\hline 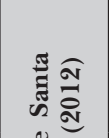 & to & $\begin{array}{l}\infty \\
0 \\
0 \\
0\end{array}$ & $\begin{array}{l}\text { v } \\
\text { d. } \\
\sigma \\
0\end{array}$ & & $=$ & $\begin{array}{c}\mathbb{N} \\
\tilde{N} \\
0\end{array}$ & $\mid \begin{array}{l}1 \\
\infty \\
+ \\
0 \\
0\end{array}$ & \begin{tabular}{|l}
0 \\
1 \\
0 \\
0 \\
0
\end{tabular} & & $\mid \begin{array}{l}0 \\
2 \\
0 \\
0 \\
0\end{array}$ & & $\begin{array}{l}\stackrel{\infty}{0} \\
0 \\
0\end{array}$ & & $\begin{array}{l}1 \\
8 \\
0\end{array}$ & $\begin{array}{l}8 \\
0 \\
0 \\
0\end{array}$ & $\begin{array}{l}\text { V. } \\
\stackrel{8}{\delta} \\
0\end{array}$ & $\begin{array}{l}\infty \\
\stackrel{0}{N} \\
0 \\
0\end{array}$ & \\
\hline 焉 & 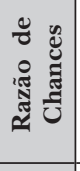 & F & $\begin{array}{l}\mathscr{D} \\
\mathscr{D} \\
0 \\
0\end{array}$ & $\mid \begin{array}{c}8 \\
8 \\
-1\end{array}$ & $\begin{array}{l}0 \\
10 \\
0 \\
0\end{array}$ & $\mid \begin{array}{l}\mathrm{N} \\
\mathrm{N} \\
0 \\
0\end{array}$ & $\begin{array}{l}10 \\
10 \\
0 \\
0 \\
0\end{array}$ & $\begin{array}{c}0 \\
0 \\
0 \\
-1 \\
-1\end{array}$ & $\begin{array}{l}8 \\
\vdots \\
- \\
-\end{array}$ & $\begin{array}{l}\bar{\sigma} \\
\stackrel{\infty}{-}\end{array}$ & $\mid \begin{array}{c}0 \\
0 \\
- \\
-1\end{array}$ & 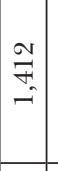 & $\underset{8}{8}$ & $\begin{array}{l}20 \\
9 \\
0 \\
0 \\
\end{array}$ & $\underset{\leftarrow}{\stackrel{\varpi}{F}}$ & $\begin{array}{l}\text { an } \\
\stackrel{1}{0} \\
\text { ô }\end{array}$ & $\begin{array}{l}\hat{N} \\
\text { N } \\
- \\
-\end{array}$ & $\stackrel{8}{\circ}$ \\
\hline 疍 $\widehat{O}$ & 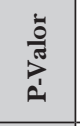 & O. & $\begin{array}{l}\mathcal{V} \\
\mathcal{N} \\
0 \\
0\end{array}$ & & $\begin{array}{l}\text { Yै } \\
\text { f } \\
0\end{array}$ & $\begin{array}{l}10 \\
10 \\
10 \\
0\end{array}$ & $\begin{array}{l}\text { N } \\
\text { S. } \\
0\end{array}$ & $\begin{array}{l}0 \\
0 \\
0 \\
0\end{array}$ & & $\begin{array}{l}10 \\
0 \\
0\end{array}$ & & $\begin{array}{l}\infty \\
\infty \\
2 \\
0 \\
0\end{array}$ & & $\begin{array}{l}8 \\
8 \\
0\end{array}$ & $\begin{array}{l}8 \\
8 \\
0\end{array}$ & $\begin{array}{l}\infty \\
\stackrel{20}{8} \\
0\end{array}$ & 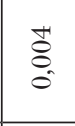 & \\
\hline 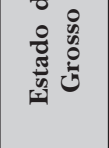 & 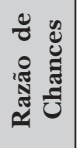 & $\begin{array}{l}8 \\
8 \\
0\end{array}$ & $\begin{array}{l}\mathcal{N} \\
2 \\
\sigma \\
0 \\
0\end{array}$ & $\underset{-}{8}$ & $=$ & $\begin{array}{l}1 \\
20 \\
0 \\
-1\end{array}$ & $\underline{\tilde{g}}$ & $\begin{array}{l}20 \\
0 \\
-1\end{array}$ & $\begin{array}{l}8 \\
\vdots \\
- \\
-1\end{array}$ & $\mid \begin{array}{l}\mathbb{N} \\
\text { Na } \\
\stackrel{-}{-}\end{array}$ & 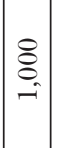 & 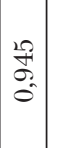 & $\underset{8}{8}$ & $\begin{array}{l}F \\
\vec{f} \\
\hat{i}\end{array}$ & $\stackrel{+}{8}$ & م⿱ & $\stackrel{\infty}{\stackrel{2}{+}}$ & $\stackrel{8}{-}$ \\
\hline$\stackrel{0}{0}$ & 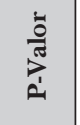 & $\begin{array}{l}8 \\
8 \\
0 \\
0\end{array}$ & $\begin{array}{l}8 \\
0 \\
0\end{array}$ & & $\stackrel{8}{\circ}$ & $\begin{array}{l}8 \\
8 \\
0\end{array}$ & $\begin{array}{l}8 \\
8 \\
0\end{array}$ & $\begin{array}{l}8 \\
8 \\
0\end{array}$ & & $\begin{array}{l}8 \\
8 \\
0\end{array}$ & & $\begin{array}{l}8 \\
8 \\
0 \\
0\end{array}$ & & $\begin{array}{l}8 \\
8 \\
0\end{array}$ & $\stackrel{8}{8}$ & $\stackrel{8}{8}$ & $\stackrel{8}{8}$ & \\
\hline 䒕 & 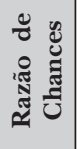 & $\begin{array}{l}0 \\
8 \\
0\end{array}$ & $\stackrel{+}{\stackrel{+}{o}}$ & $\underset{-}{8}$ & $\begin{array}{l}\text { है } \\
\text { مै } \\
\text { مै }\end{array}$ & 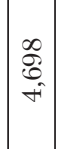 & $\begin{array}{l}10 \\
\infty \\
\infty \\
-1\end{array}$ & 息 & $\underset{8}{8}$ & $\left|\begin{array}{l}2 \\
\infty \\
1 \\
0 \\
0\end{array}\right|$ & 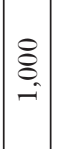 & $\begin{array}{l}0 \\
\exists \\
= \\
=\end{array}$ & $\underset{8}{8}$ & $\begin{array}{l}\exists \\
\vec{z} \\
\hat{v}\end{array}$ & $\begin{array}{l}10 \\
\infty \\
10 \\
-1\end{array}$ & $\stackrel{\infty}{\mathscr{0}}$ & $\stackrel{\stackrel{g}{I}}{=}$ & $\stackrel{8}{-}$ \\
\hline & & & 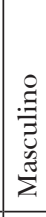 & 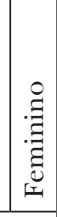 & 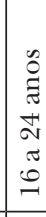 & 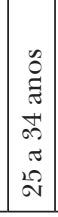 & 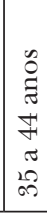 & 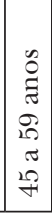 & 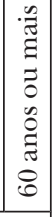 & 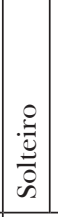 & 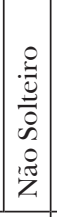 & 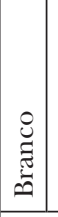 & $\begin{array}{l}0 \\
\stackrel{0}{0} \\
\dot{Z}\end{array}$ & 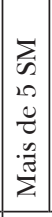 & 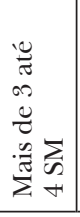 & 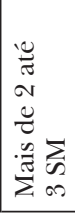 & 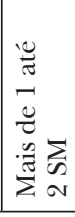 & 㳫 \\
\hline & & $\begin{array}{l}0 \\
0 \\
0 \\
0 \\
0 \\
\Xi \\
\Xi\end{array}$ & & 串 & & & 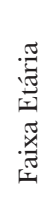 & & & 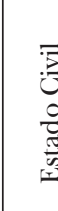 & 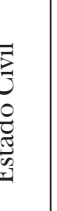 & نَ & ذَّ & & & 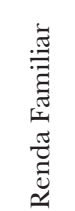 & & \\
\hline
\end{tabular}




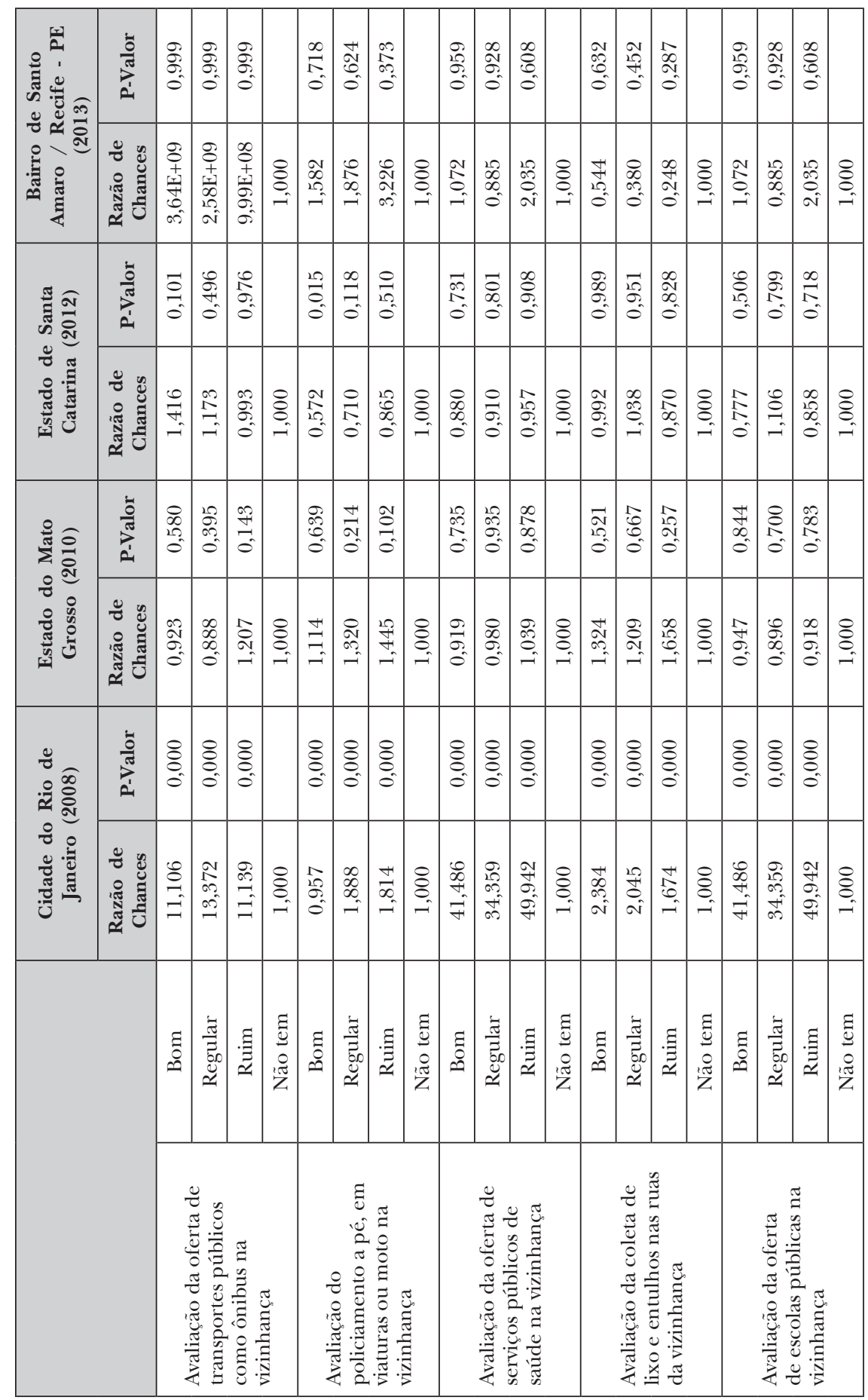




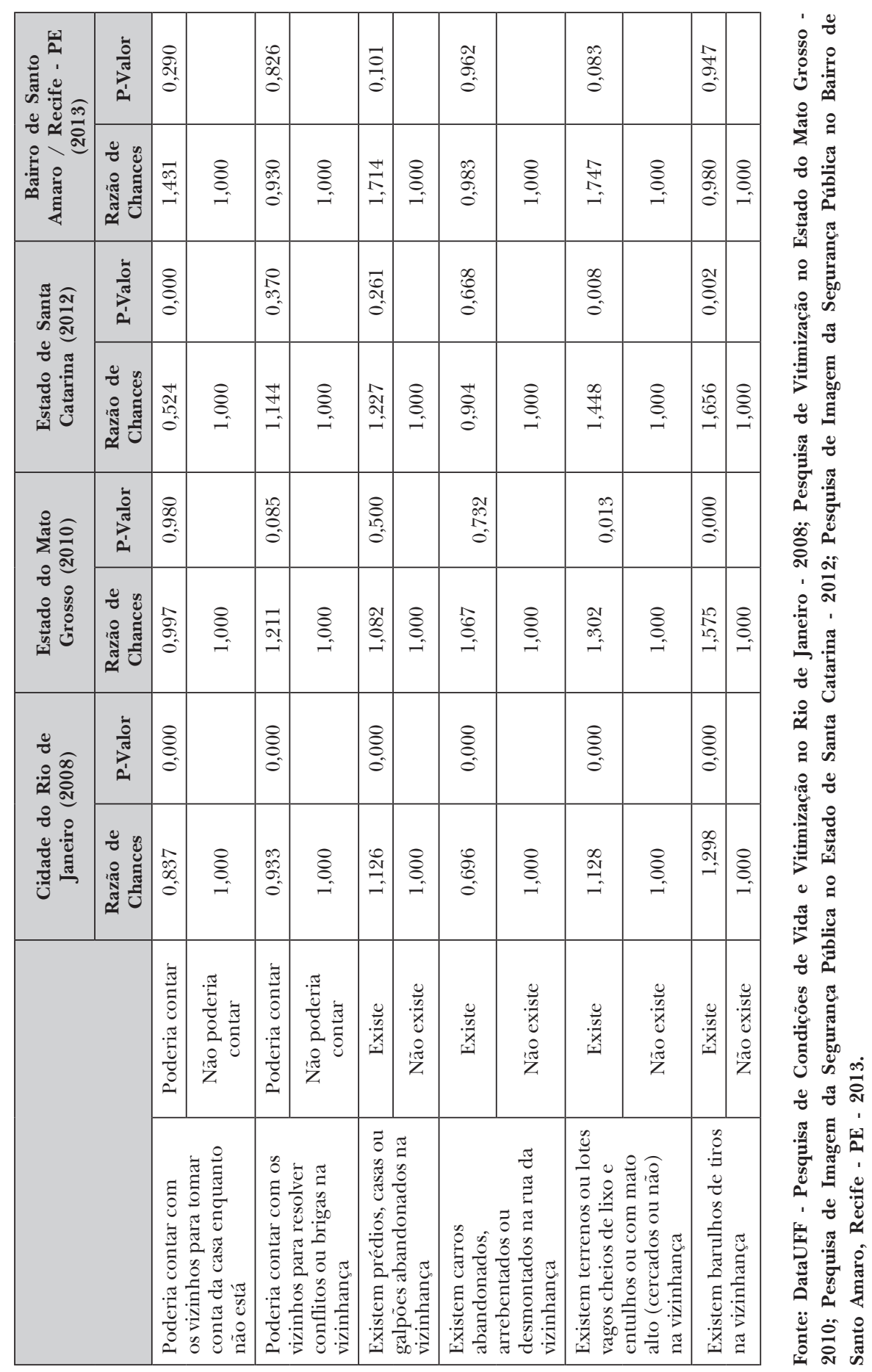


Outra abordagem importante desenvolvida pelos estudiosos da vitimização são os laços sociais na vizinhança. Segundo os autores, quando os vizinhos podem contar uns com os outros, os riscos de vitimização diminuem (SAMPSON; GROVES, 1989; WARNER; ROUNTREE, 1997; SAMPSON, 2004). Essa hipótese foi confirmada nos modelos da Cidade do Rio de Janeiro e do Estado de Santa Catarina.

Alguns pesquisadores têm procurado mostrar a relação dos indicadores de desordem com o medo do crime e a vitimização. Ao abordar essa relação, procura-se apontar a importância da dimensão de desordem física e social como possível causa dos elevados níveis de criminalidade, medo do crime e insegurança (WILSON; KELLING, 1982; SKOGAN, 1990; KELLING; COLES, 1996). Pesquisas têm confirmado essa relação e demonstrado que elevados níveis de desordem na vizinhança produzem maiores taxas de criminalidade, geram maior medo e insegurança para a população (SKOGAN, 1990). Nessa análise, encontramos um resultado coerente com a literatura para a Cidade do Rio de Janeiro e para os Estados do Mato Grosso e Santa Catarina.

Em suma, o objetivo principal deste artigo foi o de estender a literatura que aborda a relação entre o controle social e a vitimização patrimonial, controlando os efeitos através de dois níveis: individual e de vizinhança. Analisando os efeitos da dimensão individual sobre a vitimização, encontramos efeitos significativos para a compreensão da vitimização por crimes contra patrimônio para os locais estudados. No entanto, ao estudar os efeitos da vizinhança, verificamos que os resultados foram consistentes com a literatura para algumas das localidades analisadas. De qualquer forma, podemos concluir que a vizinhança desempenha um papel importante na explicação da vitimização patrimonial em termos de efeitos "principais". Ou seja, os contextos com níveis mais elevados de controle e coesão social tendem a acentuar a natureza protetora dos esforços individuais de proteção da vizinhança (SAMPSON, 2004). Assim como os ambientes com maior desordem física e tendem a apresentar mais chances de vitimização patrimonial (WILSON; KELLING, 1982; SKOGAN, 1990; KELLING; COLES, 1996). Como tal, encontramos apoio para a ideia de que o fornecimento de proteção mútua aumenta os custos do mercado associados com o crime, o que reforça as práticas de coesão e controle social e controle social público (SKOGAN; HARTNETT, 1997).

Assim, verificamos que o risco de vitimização pode ser explicado tanto por fatores do nível do indivíduo quanto da vizinhança, mas que os efeitos não são homogêneos nas comparações realizadas neste trabalho. 


\section{Conclusão}

Dados de diferentes estudos sugerem que a violência tem vários aspectos e condições, que são desigualmente distribuídos no meio social, sugerindo que alguns grupos apresentam maiores riscos de vitimização do que outros, e as formas para resolver os conflitos interpessoais podem ser promovidos por um processo interativo entre instituições formais e a comunidade. Nessa perspectiva, este estudo apresentou uma análise da vitimização a partir da interpretação da influência de aspectos individuais e da vizinhança sobre o risco de ser vitimado. Para tanto, foram consideradas algumas abordagens teóricas que consideram a convergência entre o tempo e o espaço (teorias das atividades de vida e estilo de vida), e as condições sociais e físicas da vizinhança (controle social público, laços sociais, desordem física e social).

Ademais, uma das motivações para o desenvolvimento deste estudo foi a averiguação do potencial de generalização da explicação do risco de vitimização criminal a partir dos modelos de regressão logística, com base na perspectiva teórica referenciada neste trabalho. Com base nos resultados apresentados, podemos concluir que não existem evidências substantivas para a generalização dos resultados. $\mathrm{Na}$ análise comparativa das quatro pesquisas realizadas pelo DataUFF, percebemos que não existe um modelo padrão para explicar o fenômeno da vitimização para a Cidade do Rio de Janeiro, os Estados de Mato Grosso e Santa Catarina e o Bairro Santo Amaro. No que concerne aos fatores do indivíduo e da vizinhança, verificamos que as razões de chance para a vitimização de roubo e furto variam nas quatro localidades estudadas.

Portanto, nossos resultados sugerem três principais conclusões em termos dos efeitos da vitimização: (1) que os efeitos de vizinhança são importantes para explicar o risco de vitimização de roubo ou furto, (2) que os efeitos das características individuais e de vizinhança não são generalizáveis em contextos sociais distintos, e (3) que, controlando por fatores dos indivíduos, e com a adição de características da vizinhança nos modelos, o fenômeno da vitimização por roubo e furto pode ser mais bem explicado.

Vale destacar, também, uma abordagem apresentada na discussão teórica e nos resultados empíricos encontrados neste trabalho: o controle social público. Essa abordagem não só deve ser entendida como um caminho para a melhoria da comunidade em si, mas como a viabilidade ou o desenvolvimento político em bairros mais desfavorecidos. Em contraste com a visão de que os moradores de áreas menos abastadas são necessariamente mais alienados no 
que se refere às relações com as instituições políticas e têm atitudes apáticas em direção ao andamento das políticas, o efeito do controle social público sugere que os bairros desfavorecidos exercem contextos politicamente viáveis para o sucesso de programas sociais ou planejamentos estratégicos desenvolvidos por parte do governo. Essa observação é apoiada claramente pelo importante papel que os moradores desempenham no estabelecimento do controle social público. A literatura sobre a mobilização do bairro salienta a influência que os moradores podem dar para as políticas locais, quando eles são organizados e usam táticas de pressão (ROONEY, 1995; RABRENOVIC, 1996). Tais ações, por sua vez, muitas vezes, têm obrigado as autoridades a alocarem recursos nesses bairros.

Da mesma forma, a ideia do policiamento comunitário é iniciar laços entre a polícia e os moradores. Na medida em que esses laços são fortalecidos, o programa de policiamento comunitário torna-se mais bemsucedido (KELLING; COLES, 1996). De fato, um dos principais objetivos do policiamento comunitário é promover a autoajuda e fornecer à comunidade mecanismos de controle social informal que ponham em marcha o processo de tomada de posse da própria comunidade (SKOGAN, 1990).

Nosso entendimento sobre o controle social público está relacionado aos laços entre os moradores e o governo, bem como à garantia dos recursos para o desenvolvimento das políticas na vizinhança ou no bairro. Acreditamos que o controle social público é uma perspectiva teórica relevante, tendo em vista que esta apresenta a vizinhança como um espaço com condições politicamente viáveis para o desenvolvimento de políticas públicas para a redução da vitimização criminal. Os resultados deste trabalho corroboram com essa afirmação para algumas das localidades estudadas. Nesse sentido, podemos concluir que a articulação entre a gestão pública e os moradores de localidades desfavorecidas para o desenvolvimento de políticas públicas de redução e prevenção da violência e da criminalidade pode ser uma estratégia fundamental para o alcance da tão esperada "qualidade de vida".

\section{Referências}

BEATO, Claudio; PEIXOTO, Betânia Totino; ANDRADE, Mônica Viegas.

(2004). Crime, oportunidade e vitimização. Revista Brasileira de Ciências Sociais, 19(55), p.73-89.
BORGES, Doriam.

(2013). Vitimização e Sentimento de Insegurança no Brasil em 2010: Teoria, análise e contexto. Revista Mediações, n. 18. 
(2008). Vitimização Criminal: Prevalência, Incidência e o Estilo de Vida. In: Andréia Soares Pinto; Renato Dirk; Vanessa Campagnac (Orgs.); Pesquisa de Condições de Vida e Vitimização - 2007. Rio de Janeiro: Instituto de Segurança Pública.

BRAITHWAITE, John; BILES, David.

(1984). Victims and Offenders: The Australian Experience. In: Richard Block (Ed.); Victimization and fear of crime: World perspectives 3. National Criminal Justice Reference Service / National Institute of Justice - United States Department of Justice.

BURSIK, Robert.

(1989). Social Disorganization Theories of Crime and Delinquency: Problems and Prospects. Criminology, n. 26, p. 519-551.

BURSIK, Robert; GRASMICK, Harold.

(1993). Neighborhoods and Crime: The Dimensions of Effective Community Control. New York: Lexington Books.

CALDEIRA, TEREZA.

(2000). Cidade de Muros: crime, segregação e cidadania em São Paulo. São Paulo - Edusp.

COHEN, Lawrence; CANTOR, David.

(1980). The determinants of larceny: An empirical and theoretical study. Journal of Research in Crime and Delinquency, n. 17, $\mathrm{p}$ 140-159.

COHEN, LAWRENCE; FELSON, MARCUS

(1979). Social change and crime rate trends: a routine activity approach. American Sociological Review, n. 44, p. 588-608.

COHEN, LAWRENCE; KLUEGEL, JAMES; LAND, KENNETH

(1981). Social Inequality and Predatory Criminal Victimization: An Exposition and Test of a Formal Theory. American Sociological Review, v. 46, p. 505-524.

CORRADO, RAYMOND; ROESCH, RONALD; GLACKMAN, WILLIAN; EVANS, JOHN; LEGER, GERALD

(1980). Life Styles and Personal Victimization: A Test of the Model with Canadian Survey
Data. Journal of Crime and Justice, n. 3, p. 129-139.

DAWLEY, David.

(1992). A Nation of Lords: The autobiography of the Vice Lords. Prospect Heights, Waveland Press.

FELSON, Marcus; COHEN, Lawrence.

(1980). Human ecology and crime: a routine activity approach. Humam Ecology, vol. 8, p.389-406.

GAROFALO, James.

(1987). Reassessing the lifestyle model of criminal victimization. In: Michael Gottfredson; Travis Hirschi (Eds.); Positive Criminology. Newbury Park, CA: Sage. p. 2342.

GOTTFREDSON, Michael; HINDELANG, Michael.

(1981). Sociological aspects of criminal victimization. Annual Review of Sociology, n. 7, p. 107-128.

GOTTFREDSON, Michael.

(1986). Substantive contributions of victimizations surveys. In: Norval Morris; Michael Tonry; (Eds). Crime and Justice: An annual review of research, v. 7, p. 251-288. Chicago: University of Chicago Press.

HACKING, Ian.

(1990). The taming of chance. Cambridge University Press.

HENNING, John.

(1982). Criminal Justice Reform (From Criminal Justice System in America, 1982, Part 3-See NCJ-93023).

HINDELANG, Marcus.

(1976). Criminal victimization in eight American cities: A descriptive analysis of common theft and assault. Cambridge, Mass: Ballinger Publishing Company.

HINDELANG, Michael; GOTTFREDSON, Michael; GAROFALO, James.

(1978). The Victims of Personal Crime: An Empirical Foundation for a Theory of Personal Victimization. Cambridge, MA: Ballinger. 
HOUGH, Mike; MAYHEW, Patricia.

(1983). The British crime survey: first report, London.

HUNTER, Albert.

(1985). Private, parochial and public school orders: The problem of crime and incivility in urban communities. In: Gerald Suttles; Mayer Zald (Eds.); The Challenge of Social Control: Citizenship and Institution Building in Modern Society. Norwood, J=NJ: Ablex Publishing.

KELLING, George; COLES, Catherine.

(1996). Fixing Broken Windows: Restoring Order and Reducing Crime in Our Communities. New York: Free Press.

KENNEDY, Leslie; FORDE, David.

(1990). Routine activities and crime: An analysis of victimization in Canada. Criminology, n. 28, p. 137-151.

KRIV0, Lauren; PETERSON, Ruth.

(1996). Extremely disadvantaged neighborhoods and urban crime. Social Forces, n. 75, p. 619-650.

LAHOSA, Joseph.

(2002). Delincuencia y ciudad. Hacia una reflexión geográfica comprometida. Revista bibliográfica de geografía y ciencias sociales, Vol. VII. Disponivel em: http://www.ub.es/ geocrit/b3w-349.html. Acesso em agosto de 2013.

MASSEY, Douglas; DENTON, Nancy.

(1993). American Apartheid: Segregation and the making of the underclass. Cambridge, Mass: Harvard University Press.

MAXFIELD, Michael.

(1987). Explaining the Fear of Crime: Evidence from the 1984 British Crime Survey. Home Office Research Study, n. 41. London: Home Office.

MIETHE, Terence; STAFFORD, Mark; LONG, Scott.

(1987). Social differentiation in criminal victimization: A test of routine activities / lifestyle theories. American Sociological Review, n. 52, p. 184-194.
MIETHE, Terance; MEIER, Robert.

(1994). Crime and its social context: Toward an Integrated theory of offenders, victims, and situations. Albany: State University of New York Press.

PIQUERO, Alex; GREENE, Jack; FYFE, James; KANE, Robert; COLLINS, Peter.

(1998). Implementing community policing in public housing developments in Philadelphia: Some early results. In: Geoffrey Alpert; Alex Piquero (Eds.); Community Policing: Contemporary reading. Prospect Heights: Waveland Press.

PIQUET, Leandro; FAJNZYLBER, Pablo.

(2001). A Criminalidade nas Regiões Metropolitanas do Rio de Janeiro e São Paulo: Determinantes da Vitimização e Políticas Públicas. In: Pablo Fajnzyber; Daniel Lederman; Norman Loyaza (Orgs.); Crime e Violência na América Latina. Banco Mundial/ Alfaomega.

RABRENOVIC, Gordana.

(1996). Community builders: A tale of neighborhood mobilization in two cities. Philadelphia: Temple University Press.

ROONEY, Jim.

(1995). Organizing the South Bronx. Albany: State University of New York Press.

ROUNTREE, Pamela; LAND, Kenneth; MIETHE, Terence.

(1994). Macro-micro integration in the study of victimization: A hierarchical logistic model analysis across Seattle neighborhoods. Criminology, n. 32, p. 387-414.

SAMPS0, Robert; RAUDENBUSH, Stephen; EARLS, Felton.

(1997). Neighborhoods and Violent Crime: A Multilevel Study of Collective Efficacy. Science, 277, p.918-24.

SAMPSON, Robert; GROVES, Bryron.

(1989). Community Structure and Crime: Testing Social Disorganization Theory. American Journal of Sociology, 94, p.774-802. 
SAMPSON, Robert; LAURITSEN, Janet.

(1994). Violent victimization and offending: Individual-, situational-, and community-level risk factors. Understanding and preventing violence, v. 3, p. 1-114.

SAMPSON, Robert; WOOLREDGE, John.

(1987). Linking the micro and macro-level dimensions of livestyle-routine activity and opportunity models of predatoryvictimization. Journal of Quantitative Criminology, n. 3, p. 371-393.

SAMPSON, Robert.

(2004). Neighborhood and Community: Collective Efficacy and Community Safety. New Economy, 11, p.106-13.

SHAW, Clifford; MCKAY, Henry.

(1942). Juvenile delinquency and urban areas. Chicago: University of Chicago.

SKOGAN, Wesley; MAXFIELD, Michael.

(1981). Coping with Crime. Beverly Hills: Sage.

SKOGAN, Wesley.

(1990). Disorder and Decline: Crime and the Spiral of Decay in American Neighborhoods. New York: The Free Press.

SKOGAN, Wesley; HARTNERR, Susan. (1997). Community policing. Chicago Style. New York: Oxford University Press.

SMITH, Douglas.

(1982). Invoking the law: Determinants of police arrest decisions. Dissertation. Indiana University.
VAN DIJK, Jan; STEINMETZ, Carl.

(1983).Victimization surveys: Beyond measuring the volume of crime. Victimology.

WACQUANT, Loic; WILSON, Willian.

(1989). The cost of racial and class exclusion in the inner city. Annuals of the American Academy of political and social science, n. 501, p. 8-25.

WARNER, Barbara; ROUNTREE, Pamela.

(1997). Local social ties in a community and crime model: Questioning the systemic nature of informal social control. Social Problems, n. 44, p. 520-536.

WILSON, Willian.

(1996). When work disappears: The world of the new urban poor. New York: Random House.

WILSON, James; KELLING, George.

(1982). Broken Windows. Atlantic Monthly. p. 29-38.

\section{Recebido em}

fevereiro de 2014

\section{Aprovado em}

julho de 2014 


\begin{tabular}{|c|c|c|c|c|c|c|c|c|c|c|c|c|c|c|c|c|c|c|}
\hline \multirow{3}{*}{ 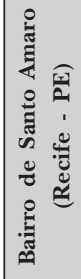 } & $\ddot{\infty i n}$ & $\begin{array}{l}\mathscr{g} \\
\dot{S} \\
\dot{0}\end{array}$ & $\begin{array}{l}\overrightarrow{0} \\
\tilde{2} \\
0\end{array}$ & $\begin{array}{l}q \\
\vdots \\
0 \\
0\end{array}$ & $\begin{array}{l}+ \\
\infty \\
\infty \\
0 \\
0\end{array}$ & $\begin{array}{l}10 \\
\text { in } \\
12 \\
0\end{array}$ & $\left|\begin{array}{l}20 \\
\stackrel{9}{0} \\
0 \\
0\end{array}\right|$ & $\begin{array}{l}\infty \\
\infty \\
0 \\
0\end{array}$ & 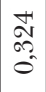 & $\begin{array}{l}1 \\
0 \\
10 \\
0 \\
0\end{array}$ & $\begin{array}{c}0 \\
\stackrel{1}{2} \\
2 \\
0\end{array}$ & $\begin{array}{l}\infty \\
0 \\
0 \\
0 \\
0\end{array}$ & $\mid \begin{array}{c}8 \\
\stackrel{2}{2} \\
\tilde{0}\end{array}$ & $\mid \begin{array}{l}0 \\
\mathscr{1} \\
0 \\
0 \\
0\end{array}$ & $\begin{array}{l}\overrightarrow{0} \\
\overrightarrow{0}\end{array}$ & $\begin{array}{l}\tilde{o} \\
\mathscr{b} \\
0 \\
0\end{array}$ & $\begin{array}{l}\infty \\
\infty \\
0 \\
0 \\
0\end{array}$ & $\begin{array}{l}\frac{1}{4} \\
\text { S. } \\
0\end{array}$ \\
\hline & 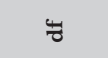 & $\neg$ & - & H & - & - & + & $\infty$ & or & $\infty$ & $\infty$ & $\infty$ & - & -7 & $\neg$ & -1 & - & - \\
\hline & 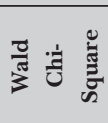 & 8 & : & $\begin{array}{l}q \\
i v \\
v\end{array}$ & $\begin{array}{l}0 \\
0 \\
0 \\
0\end{array}$ & ㅇ. & \begin{tabular}{l}
$\approx$ \\
\multirow{N}{*}{}
\end{tabular} & $\begin{array}{l}20 \\
20 \\
20\end{array}$ & $\frac{\infty}{\infty}$ & $\begin{array}{l}\infty \\
\infty \\
0 \hat{v} \\
\hat{v}\end{array}$ & $=$ & $\begin{array}{l}0 \\
\infty \\
\infty\end{array}$ & $\begin{array}{l}\approx \\
= \\
=\end{array}$ & \begin{tabular}{|l|}
20 \\
0 \\
0 \\
0
\end{tabular} & $\begin{array}{l}8 \\
\dot{0} \\
\text { i }\end{array}$ & $\begin{array}{l}8 \\
0 \\
0\end{array}$ & $\begin{array}{l}8 \\
\text { on }\end{array}$ & 8 \\
\hline \multirow{3}{*}{ 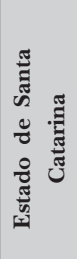 } & 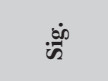 & $\begin{array}{l}8 \\
0 \\
0 \\
0\end{array}$ & $\mid \begin{array}{l}2 \\
\sigma \\
2 \\
0 \\
0\end{array}$ & $\begin{array}{l}9 \\
0 \\
0 \\
0 \\
0\end{array}$ & $\begin{array}{l}1 \\
20 \\
0 \\
0\end{array}$ & $\begin{array}{l}\text { aq } \\
0 \\
0\end{array}$ & $\begin{array}{l}\overline{0} \\
\dot{8} \\
0 \\
0\end{array}$ & $\begin{array}{l}\frac{8}{\circ} \\
0\end{array}$ & $\begin{array}{l}12 \\
20 \\
0\end{array}$ & $\mid \begin{array}{l}1 \\
8 \\
0 \\
0\end{array}$ & $\left|\begin{array}{l}7 \\
5 \\
0 \\
0\end{array}\right|$ & $\begin{array}{l}\mathscr{\sigma} \\
\mathscr{\sigma} \\
\tilde{0}\end{array}$ & $\left|\begin{array}{l}0 \\
0 \\
0 \\
0\end{array}\right|$ & $\mid \begin{array}{c}0 \\
0 \\
0 \\
0 \\
0\end{array}$ & $\begin{array}{l}\vec{b} \\
\tilde{n} \\
0\end{array}$ & $\mid \begin{array}{l}0 \\
0 \\
0 \\
0\end{array}$ & $\begin{array}{l}\infty \\
0 \\
0 \\
0\end{array}$ & $\begin{array}{l}\text { Oे } \\
\text { Oे } \\
0 \\
0\end{array}$ \\
\hline & 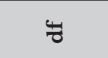 & $\neg$ & -7 & H & $\neg$ & - & + & $\infty$ & $\infty$ & $\infty$ & $\infty$ & $\infty$ & - & - & -1 & -1 & - & - \\
\hline & 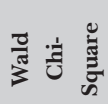 & $\begin{array}{l}\text { N } \\
\text { 至 }\end{array}$ & $\begin{array}{l}0 \\
0 \\
0\end{array}$ & $\stackrel{\mathscr{F}}{\rightarrow}$ & $\begin{array}{c}0 \\
0 \\
\infty\end{array}$ & $\exists$ & $\mid \begin{array}{l}0 \\
2 \\
2 \\
2\end{array}$ & $\begin{array}{l}\stackrel{N}{N} \\
+\end{array}$ & $\frac{5}{2}$ & $\begin{array}{l}1 \\
\tilde{y} \\
0 \\
0\end{array}$ & $\left|\begin{array}{l}\infty \\
\infty \\
0 \\
0\end{array}\right|$ & \begin{tabular}{l}
$m$ \\
$\stackrel{m}{*}$ \\
\multirow{4}{*}{}
\end{tabular} & $\left|\begin{array}{l}0 \\
2 \\
6 \\
0 \\
-1\end{array}\right|$ & $\begin{array}{l}\infty \\
\infty \\
0\end{array}$ & $\begin{array}{l}\stackrel{2}{2} \\
\sim \\
-\end{array}$ & $\frac{\infty}{1}$ & 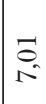 & $\begin{array}{l}1 \\
20 \\
\sigma\end{array}$ \\
\hline \multirow{3}{*}{ 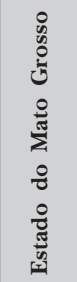 } & $\ddot{n}$ & $\begin{array}{l}8 \\
8 \\
0 \\
0\end{array}$ & $\mid \begin{array}{l}\mathcal{V} \\
\mathcal{Z} \\
0 \\
0\end{array}$ & 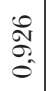 & \begin{tabular}{|l|}
10 \\
0 \\
0 \\
0
\end{tabular} & $\mid \begin{array}{l}\infty \\
\infty \\
20 \\
0\end{array}$ & $\mid \begin{array}{l}0 \\
8 \\
0 \\
0\end{array}$ & $\begin{array}{l}10 \\
12 \\
0 \\
0\end{array}$ & $\begin{array}{l}\infty \\
0 \\
0 \\
0\end{array}$ & $\mid \begin{array}{l}1 \\
20 \\
\infty 0 \\
0\end{array}$ & $\left|\begin{array}{l|}\infty \\
20 \\
2 \\
0\end{array}\right|$ & $\begin{array}{l}: \\
\mathscr{8} \\
: \\
0\end{array}$ & $\left|\begin{array}{c}0 \\
\infty \\
0 \\
0 \\
0\end{array}\right|$ & $\mid \begin{array}{l}10 \\
8 \\
0 \\
0\end{array}$ & $\begin{array}{l}8 \\
8 \\
12 \\
0\end{array}$ & $\left|\begin{array}{c}2 \\
0 \\
1 \\
0 \\
0\end{array}\right|$ & $\begin{array}{l}0 \\
0 \\
0 \\
0\end{array}$ & $\begin{array}{l}8 \\
8 \\
0\end{array}$ \\
\hline & 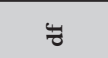 & $\rightarrow$ & - & 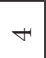 & - & $\neg$ & + & $\infty$ & $\infty$ & $\infty$ & $\infty$ & $\infty$ & - & -1 & $\neg$ & - & - & - \\
\hline & 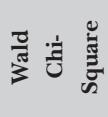 & $\begin{array}{l}1 \\
1 \\
10 \\
10\end{array}$ & $\mid$ & $\begin{array}{l}\infty \\
\infty \\
0\end{array}$ & $\begin{array}{l}8 \\
+\end{array}$ & की & $\left|\begin{array}{l}1 \\
\infty \\
\dot{e} \\
\sim\end{array}\right|$ & 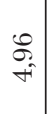 & $\begin{array}{c}10 \\
8 \\
10\end{array}$ & $\begin{array}{l}1 \\
0 \\
0\end{array}$ & $\begin{array}{l}8 \\
\approx \\
10\end{array}$ & $\begin{array}{c}0 \\
\infty \\
0\end{array}$ & $\begin{array}{l}8 \\
8 \\
0\end{array}$ & $\begin{array}{l}\mathscr{2} \\
\mathscr{2} \\
\mathrm{v}\end{array}$ & $\mid \begin{array}{l}0 \\
1 \\
0 \\
0\end{array}$ & 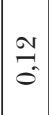 & $\frac{10}{6}$ & 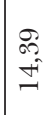 \\
\hline \multirow{3}{*}{ 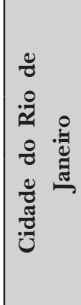 } & 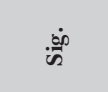 & $\begin{array}{l}8 \\
8 \\
0\end{array}$ & $\mid \begin{array}{l}8 \\
8 \\
0 \\
0\end{array}$ & $\begin{array}{l}8 \\
\vdots \\
0\end{array}$ & $\begin{array}{l}8 \\
8 \\
0 \\
0\end{array}$ & $\begin{array}{l}8 \\
8 \\
0\end{array}$ & $\begin{array}{l}0 \\
\vdots \\
0 \\
0\end{array}$ & $\begin{array}{l}8 \\
8 \\
0\end{array}$ & \&. & $\begin{array}{l}8 \\
8 \\
0 \\
0\end{array}$ & $\begin{array}{l}8 \\
8 \\
0 \\
0\end{array}$ & $\begin{array}{l}8 \\
\vdots \\
0\end{array}$ & $\mid \begin{array}{l}0 \\
\vdots \\
0 \\
0\end{array}$ & $\begin{array}{l}8 \\
8 \\
0 \\
0\end{array}$ & $\mid \begin{array}{l}0 \\
\vdots \\
0 \\
0\end{array}$ & $\begin{array}{l}0 \\
\vdots \\
0 \\
0\end{array}$ & $\begin{array}{l}8 \\
8 \\
0\end{array}$ & 8 \\
\hline & 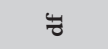 & - & - & 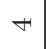 & $\neg$ & - & $\theta$ & $\infty$ & $\infty$ & $\infty$ & $\infty$ & $\infty$ & - & - & - & - & - & - \\
\hline & 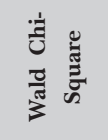 & 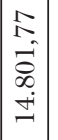 & $\begin{array}{l}0 \\
1 \\
0 \\
0 \\
\infty \\
\infty \\
\infty\end{array} \mid$ & $\begin{array}{l}10 \\
0 \\
0 \\
\mathscr{N} \\
0 \\
\infty \\
0\end{array}$ & $\mid \begin{array}{c}0 \\
\infty \\
1 \\
+ \\
+\infty \\
\infty \\
+ \\
+\end{array}$ & $\begin{array}{l}8 \\
\infty \\
\infty\end{array}$ & $\begin{array}{l}2 \\
-2 \\
20 \\
2 \\
00 \\
-1\end{array}$ & 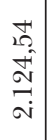 & $\begin{array}{l}20 \\
\infty \\
0 \\
0 \\
0 \\
0 \\
0\end{array}$ & $\begin{array}{c}8 \\
\mathscr{6} \\
0 \\
f \\
+ \\
-1\end{array}$ & $\left|\begin{array}{c}0 \\
- \\
+ \\
0 \\
+ \\
+\end{array}\right|$ & $\begin{array}{l}\infty \\
2 \\
2 \\
\infty \\
0 \\
0 \\
0\end{array}$ & $\mid \begin{array}{c}1 \\
0 \\
-0 \\
0 \\
0 \\
-1\end{array}$ & 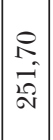 & $\begin{array}{l}2 \\
\stackrel{2}{8} \\
8\end{array}$ & $\begin{array}{l}7 \\
10 \\
0 \\
0 \\
0\end{array}$ & $\begin{array}{l}\infty \\
\text { N } \\
20 \\
\stackrel{8}{1}\end{array}$ & $\begin{array}{l}18 \\
0 \\
20 \\
0 \\
+ \\
+\end{array}$ \\
\hline & & 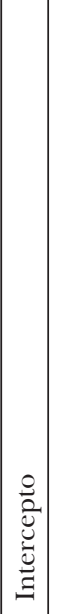 & 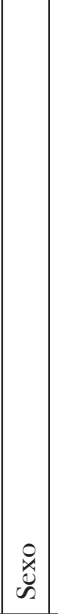 & 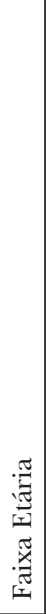 & 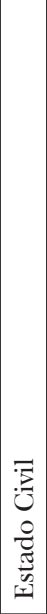 & $\ddot{0}$ & 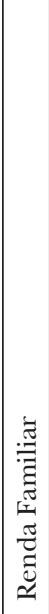 & 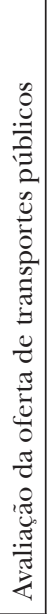 & 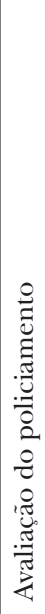 & 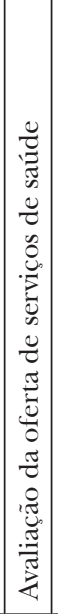 & 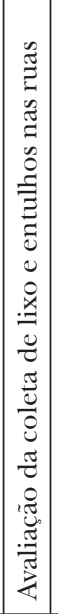 & 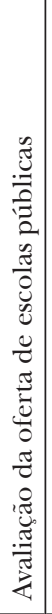 & 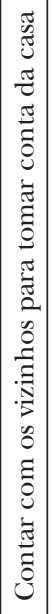 & 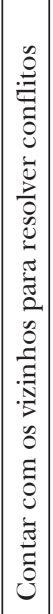 & 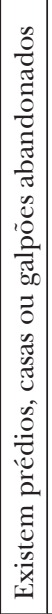 & 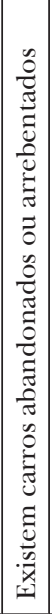 & 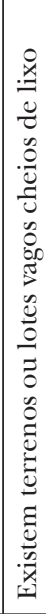 & 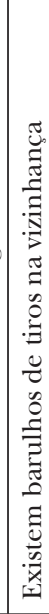 \\
\hline
\end{tabular}

